\title{
An Ultra-Sensitive Electrochemical Sensor for the Detection of Carcinogen Oxidative Stress 4-Nitroquinoline N-Oxide in Biologic Matrices Based on Hierarchical Spinel Structured $\mathrm{NiCo}_{2} \mathrm{O}_{4}$ and $\mathrm{NiCo}_{2} \mathrm{~S}_{4} ;$ A Comparative Study
}

\author{
Tse-Wei Chen ${ }^{1,+}$, Elayappan Tamilalagan ${ }^{2,+} \mathbb{0}$, Shen-Ming Chen ${ }^{2, *}$, \\ Muthumariappan Akilarasan 2(0), Selvarasu Maheshwaran ${ }^{2}$ and Xiaoheng Liu ${ }^{3, *}$ \\ 1 Department of Materials, Imperial College London, London SW7 2AZ, UK; coolman91339@gmail.com \\ 2 Department of Chemical Engineering and Biotechnology, National Taipei University of Technology, \\ Taipei 106, Taiwan; tamilalagane2014@gmail.com (E.T.); m.akil.arasann@gmail.com (M.A.); \\ maheshwarans333@gmail.com (S.M.) \\ 3 Key Laboratory of Education Ministry for Soft Chemistry and Functional Materials, Nanjing University of \\ Science and Technology, Nanjing 210094, China \\ * Correspondence: smchen78@ms15.hinet.net (S.-M.C.); xhliu@mail.njust.edu.cn (X.L.) \\ + These authors contributed equally to this work.
}

Received: 19 March 2020; Accepted: 28 April 2020; Published: 5 May 2020

check for updates

\begin{abstract}
Various factors leads to cancer; among them oxidative damage is believed to play an important role. Moreover, it is important to identify a method to detect the oxidative damage. Recently, electrochemical sensors have been considered as the one of the most important techniques to detect DNA damage, owing to its rapid detection. However, electrode materials play an important role in the properties of electrochemical sensor. Currently, researchers have aimed to develop novel electrode materials for low-level detection of biomarkers. Herein, we report the facile hydrothermal synthesis of $\mathrm{NiCO}_{2} \mathrm{O}_{4}$ micro flowers (MFs) and $\mathrm{NiCo}_{2} \mathrm{~S}_{4}$ micro spheres (Ms) and evaluate their electrochemical properties for the detection of carcinogen-causing biomarker 4-nitroquinoline n-oxide (4-NQO) in human blood serum and saliva samples. Moreover, as-prepared composites were fabricated on a glass carbon electrode (GCE), and its electrochemical activities for the determination of 4-NQO were investigated by using various electrochemical techniques. Fascinatingly, the $\mathrm{NiCo}_{2} \mathrm{~S}_{4}-\mathrm{Ms}$ showed a very low detection limit of $2.29 \mathrm{nM}$ and a wider range of 0.005 to $596.64 \mu \mathrm{M}$ for detecting 4-NQO. Finally, the practical applicability of $\mathrm{NiCo}_{2} \mathrm{~S}_{4}-\mathrm{Ms}$ in the 4-NQO spiked human blood serum and saliva samples were also investigated.
\end{abstract}

Keywords: 4-NQO detection; $\mathrm{NiCo}_{2} \mathrm{O}_{4} ; \mathrm{NiCo}_{2} \mathrm{~S}_{4}$; biologic samples; hierarchical spinel structure; hydrothermal method

\section{Introduction}

Currently, bimetallic oxide and sulfide-based nanoparticles have been widely used in the field of electrochemical application [1-3]. A well-known electrode material with superior electrocatalytic property prepared based on nickel and cobalt due its higher surface area, structures and unique morphologies than monometallic oxides or sulfides [4-8]. Thus, we have synthesized hierarchical spinel $\mathrm{NiCO}_{2} \mathrm{O}_{4}-\mathrm{MFs}$ and $\mathrm{NiCO}_{2} \mathrm{~S}_{4}-\mathrm{Ms}$ as an electrode material for the electrocatalytic reduction of 4 -NQO detection. The better response occurs on the $\mathrm{NiCO}_{2} \mathrm{~S}_{4}$-Ms modified electrode because sulfides provide the lower bandgap energy and less electronegativity than oxides [8-10]. The synthesis 
method for $\mathrm{NiCo} 2 \mathrm{~S} 4$ and $\mathrm{NiCo} 2 \mathrm{O} 4$ with various structures such as, micro flowers, nanoprism [11], nanoplates [12] and nanorods [13] and their electrocatalytic properties were previously reported. However, the hydrothermal method are more convenient to synthesis nanomaterials with different morphology then other available methods [14-16]. The chemical reaction in hydrothermal process occurs due to the influential high-temperature and pressure, which results the formation of exceptional products [17].

The term oxidative stress is defined to be the imbalance or the excessive production of reactive oxygen species (ROS) in cellular metabolism $[18,19]$. It plays an important role in living organisms such as maintenance of cell growth and production of important biologic substances, etc. [20]. However, in living organisms free radicals such as nitric oxide, peroxynitrite produce the ROS, which undergoes nitration in protein molecules, forms the 4-nitroquinoline n-oxide [21]. Thus, the excess level of 4-NQO leads to various types of disorders such as cancer, neurodegeneration and lung diseases, etc. [22]. Therefore, it is essential and important to develop analytical techniques to identify the oxidative stress biomarker 4-NQO in biologic matrices. The current analytical techniques that are used to determine 4-NQO ions are fluorescence-based screening assay, high performance liquid chromatography (HPLC) and electrochemical methods [22]. Among the aforementioned techniques, electrochemical techniques are easy to handle, require low consumption of samples, are rapid and most importantly, are low-cost [22,23]. Moreover, the fabrication of the electrode surface with the suitable materials will precisely improve the electrochemical parameters such as stability and sensitivity [24].

Herein, we reported that the facile synthesis of hierarchical spinel structure of $\mathrm{NiCO}_{2} \mathrm{~S}_{4}$ microspheres and $\mathrm{NiCo}_{2} \mathrm{O}_{4}$ micro flowers for the effective detection of oxidative stress biomarker 4-NQO. The as-prepared $\mathrm{NiCo}_{2} \mathrm{~S}_{4}$-Ms shows the excellent electrochemical activities for the determination of 4-NQO on comparing with $\mathrm{NiCO}_{2} \mathrm{O}_{4}$-MFs. Furthermore, the differential pulse voltammetry (DPV) results exhibited a low limit of detection and a wider linear range for the detection of biomarker 4-NQO. Moreover, the prepared $\mathrm{NiCO}_{2} \mathrm{~S}_{4}$-Ms shows excellent long-term stability and selectivity. Finally, real samples of the sensor were tested in 4-NQO spiked human blood serum and saliva samples.

\section{Results and Discussion}

\subsection{Microscopic and Elemental Analysis of Synthesized Nanomaterials}

The morphologic structure of synthesis nanoparticles micro flowers and microspheres were obtained using FESEM. Figure $1 \mathrm{~A}$ characteristic the morphology of $\mathrm{NiCo}_{2} \mathrm{O}_{4}$, which appears as a flower-like structure and Figure $1 \mathrm{~B}$, shows the magnified microscopic image of $\mathrm{NiCO}_{2} \mathrm{O}_{4}$ in which clearly demonstrated that the numerous nano-needles are shrinks together and forms a micro spiky structure. Moreover, the FESEM images of the $\mathrm{NiCo}_{2} \mathrm{~S}_{4}$ Figure 1C,D show that obtained particles were micro structured spheres, which were regularly distributed with an average particle size of $1.64 \mu \mathrm{m}$. Figure 2A-D illustrates the elemental mapping of $\mathrm{NiCo}_{2} \mathrm{~S}_{4} \mathrm{Ms}(\mathrm{A})$, which confirmed the presence of $\mathrm{Ni}(\mathrm{B}), \mathrm{Co}(\mathrm{C})$ and $\mathrm{S}(\mathrm{D})$ elements. In addition, the EDX analysis were taken to investigate the elemental composition present in $\mathrm{NiCo}_{2} \mathrm{~S}_{4}$ Ms. Figure 2E shows the EDX spectrum of $\mathrm{NiCo}_{2} \mathrm{~S}_{4} \mathrm{Ms}$ with the expected signal response of the elements $\mathrm{Ni}, \mathrm{Co}$ and $\mathrm{S}$. The inset image of Figure 2E presents the weight percent $\mathrm{NiCO}_{2} \mathrm{~S}_{4}$ Ms. Moreover, the elemental mapping and EDX spectrum including the weight percentage of $\mathrm{NiCo}_{2} \mathrm{O}_{4}$ MFs are presented in supplementary Figure S1A-E. 

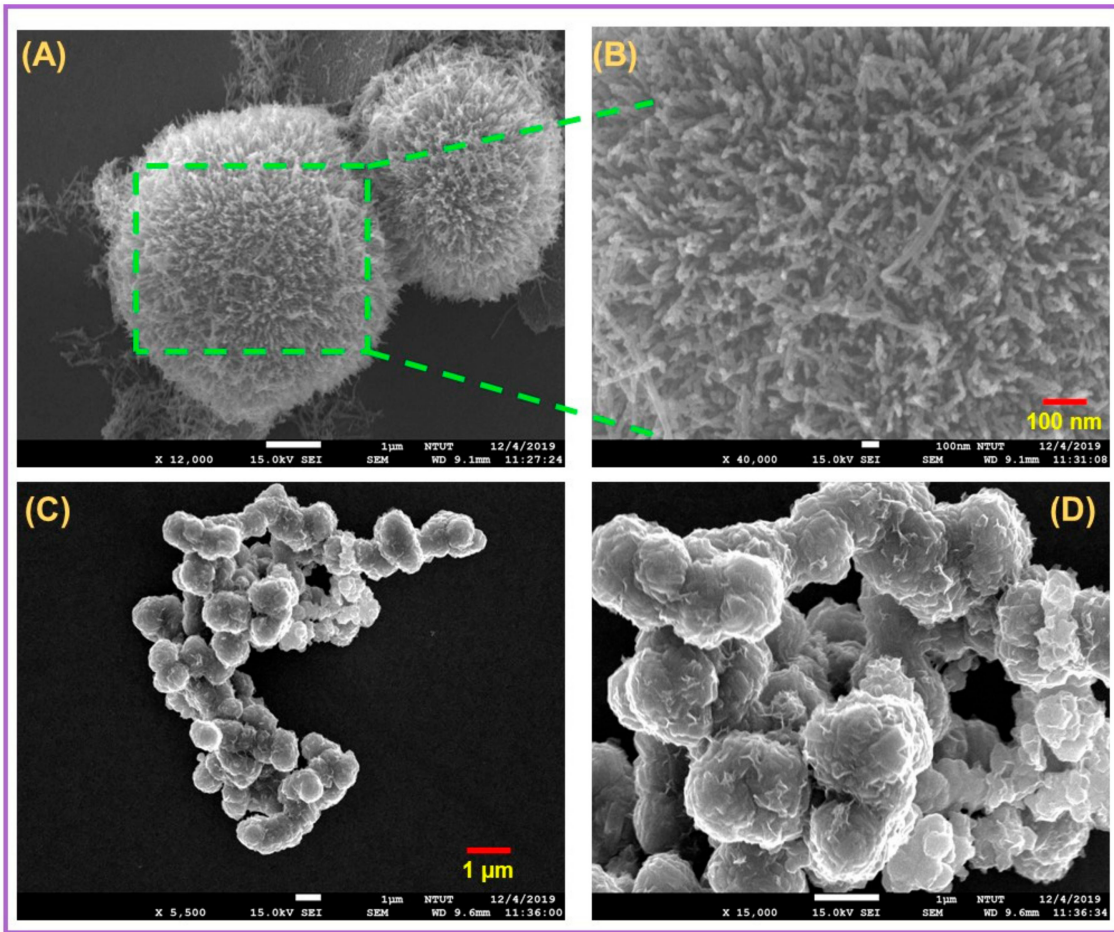

Figure 1. (A) FE-SEM of $\mathrm{NiCo}_{2} \mathrm{O}_{4}-\mathrm{MFs}$, (B) magnified image of $\mathrm{NiCo}_{2} \mathrm{O}_{4}-\mathrm{MFs}$ and (C,D) $\mathrm{NiCo}_{2} \mathrm{~S}_{4}$-Ms. Scale bar $100 \mathrm{~nm}$.

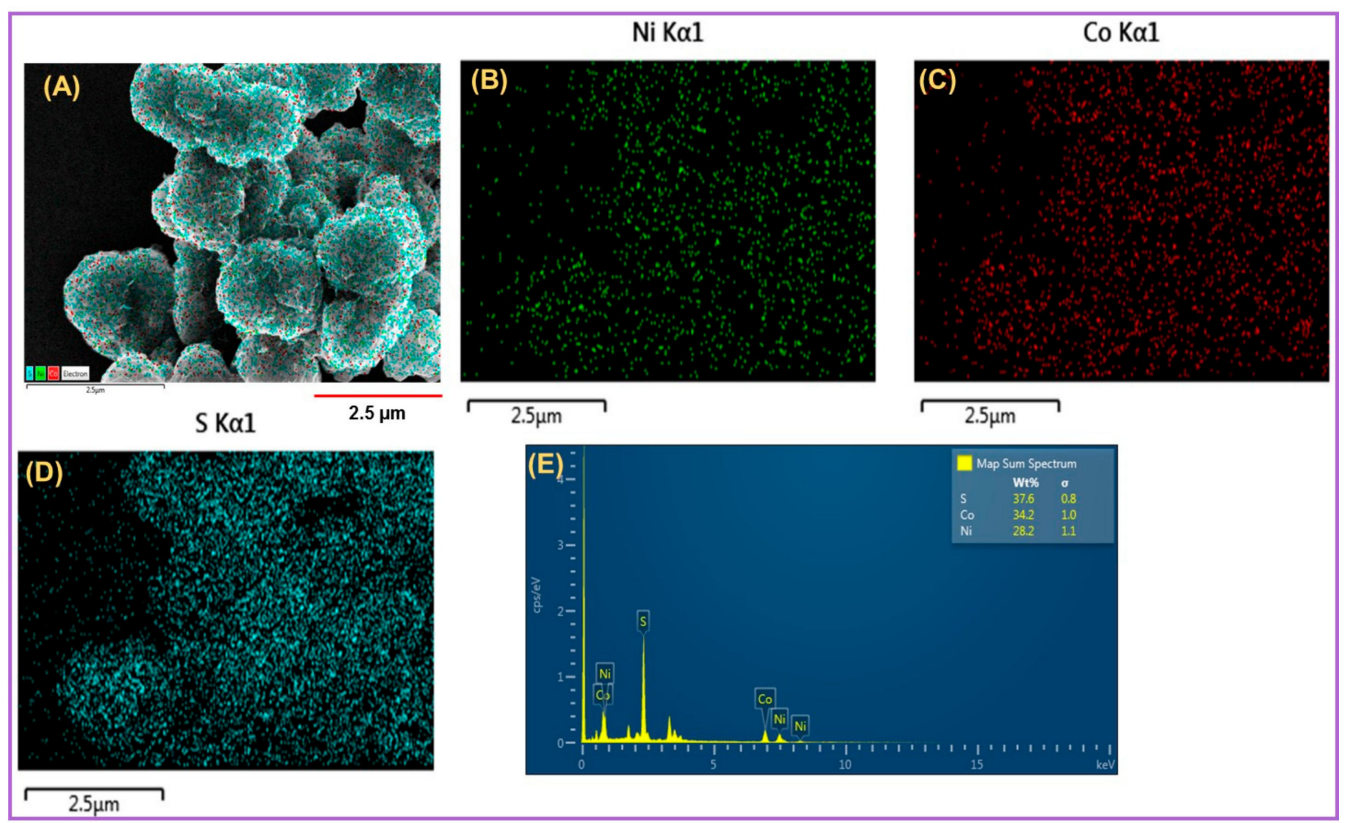

Figure 2. (A) Mapping image $\mathrm{NiCo}_{2} \mathrm{~S}_{4}$-Ms mix, (B) $\mathrm{Ni}$, (C) Co and (D) S. (E) EDX profile of $\mathrm{NiCo}_{2} \mathrm{~S}_{4}$-Ms. Inset weight percentage of $\mathrm{NiCo}_{2} \mathrm{~S}_{4}$-Ms. Scale bar $2.5 \mu \mathrm{m}$.

\subsection{XRD and XPS Analysis of $\mathrm{NiCO}_{2} \mathrm{~S}_{4}-\mathrm{Ms}$ and $\mathrm{NiCo}_{2} \mathrm{O}_{4}-\mathrm{MFs}$}

The XRD patterns of the as synthesized $\mathrm{NiCo}_{2} \mathrm{~S}_{4}-\mathrm{Ms}$ and $\mathrm{NiCo}_{2} \mathrm{O}_{4}-\mathrm{MFs}$ are shown in Figure 3A. The XRD pattern of $\mathrm{NiCo}_{2} \mathrm{~S}_{4}$-Ms Figure 3 Aa shows the characteristic peaks at $16.3^{\circ}$ (111), $26.8^{\circ}$ (220), $31.6^{\circ}(311), 38.3^{\circ}(400), 50.4^{\circ}(511), 55.3^{\circ}$ (440). These peaks were reliable with the standard XRD pattern of $\mathrm{NiCo}_{2} \mathrm{~S}_{4}-\mathrm{Ms}$ (JCPDS NO: 20-0782) [25]. Moreover, Figure $3 \mathrm{Ab}$ shows the signal response at $18.9^{\circ}(111), 31.1^{\circ}(220), 36.7^{\circ}(311), 44.6^{\circ}(400), 55.4^{\circ}$ (422), 59.1 (511), $64.9^{\circ}$ (440) shows the maximum crystallization, which confirms the formation of $\mathrm{NiCo}_{2} \mathrm{O}_{4}-\mathrm{MFs}$ (JCPDS NO: 20-0781) [26]. In addition, 
the XPS were taken to conform the chemical composition and the oxidation state of $\mathrm{NiCo}_{2} \mathrm{~S}_{4}-\mathrm{Ms}$ and $\mathrm{NiCo}_{2} \mathrm{O}_{4}-\mathrm{MFs}$. Figure $3 \mathrm{~B}, \mathrm{C}$ shows the XPS survey spectra of $\mathrm{NiCo}_{2} \mathrm{~S}_{4}-\mathrm{Ms}$ and $\mathrm{NiCo}_{2} \mathrm{O}_{4}-\mathrm{MFs}$ confirms that, the presence of $\mathrm{Ni}, \mathrm{Co}, \mathrm{S}$ and $\mathrm{O}[27,28]$. Thus, the XRD and XPS studies clearly confirms that the excellent formation of $\mathrm{NiCO}_{2} \mathrm{~S}_{4}$-Ms and $\mathrm{NiCo}_{2} \mathrm{O}_{4}$-MFs.
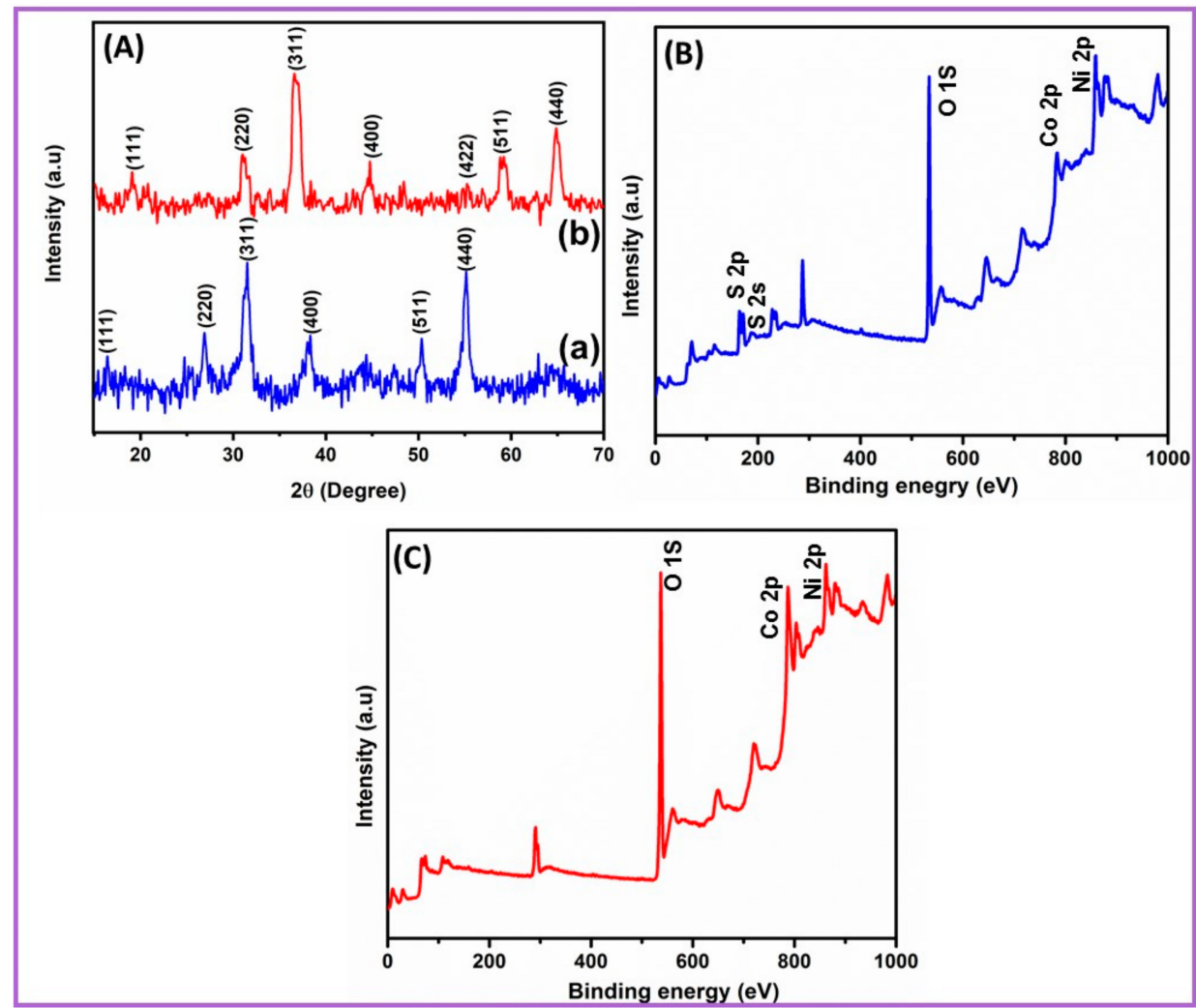

Figure 3. (A)-(a) XRD study of $\mathrm{NiCo}_{2} \mathrm{~S}_{4}-\mathrm{Ms}$ and (b) $\mathrm{NiCo}_{2} \mathrm{O}_{4}$-MFs. (B) XPS survey spectrum of $\mathrm{NiCo}_{2} \mathrm{~S}_{4}$-Ms and (C) $\mathrm{NiCO}_{2} \mathrm{O}_{4}$-MFs.

\subsection{EIS and Electrochemical Investigation of Different Electrodes}

Electrochemical impedance spectroscopy (EIS) is a method to investigate the interfacial effects between electrolyte and surface of the electrode. Figure 4A depicts the EIS curves of bare GCE (a), $\mathrm{NiCo}_{2} \mathrm{O}_{4}-\mathrm{MFs} / \mathrm{GCE}(\mathrm{b})$ and $\mathrm{NiCo}_{2} \mathrm{~S}_{4}-\mathrm{Ms} / \mathrm{GCE}$ (c) in $0.1-\mathrm{M} \mathrm{KCl}$ containing $0.05 \mathrm{M}$ of $\left[\mathrm{Fe}(\mathrm{CN})_{6}\right]^{-3 /-4}$ solution and the frequency range was set to be of $100 \mathrm{MHz}$ to $100 \mathrm{kHz}$. The obtained impedance data were fit according to the Randle's equivalent circuit model shows in the inset Figure $4 \mathrm{~A}$, where $R_{c t}$ denotes the charge transfer resistance, $Z_{\mathrm{W}}, R_{\mathrm{s}}$ and $C_{\mathrm{dl}}$ refer to Warburg impedance, ohmic resistance and the double layer electron-transfer resistance, respectively. Moreover, the $R_{c t}$ value of bare GCE, $\mathrm{NiCo}_{2} \mathrm{O}_{4}$-MFs/GCE and $\mathrm{NiCo}_{2} \mathrm{~S}_{4}$-Ms/GCE were measured to be $250.7 \Omega, 214.2 \Omega$ and 64.25 $\Omega$, respectively. As can be seen that the lowest $R_{c t}$ value were obtained for $\mathrm{NiCo}_{2} \mathrm{~S}_{4}$-Ms electrode. This was due to the microsphere structure possessing the larger surface area; when it contacted the electrolyte, it may be more effective and efficient in capturing the active materials. 

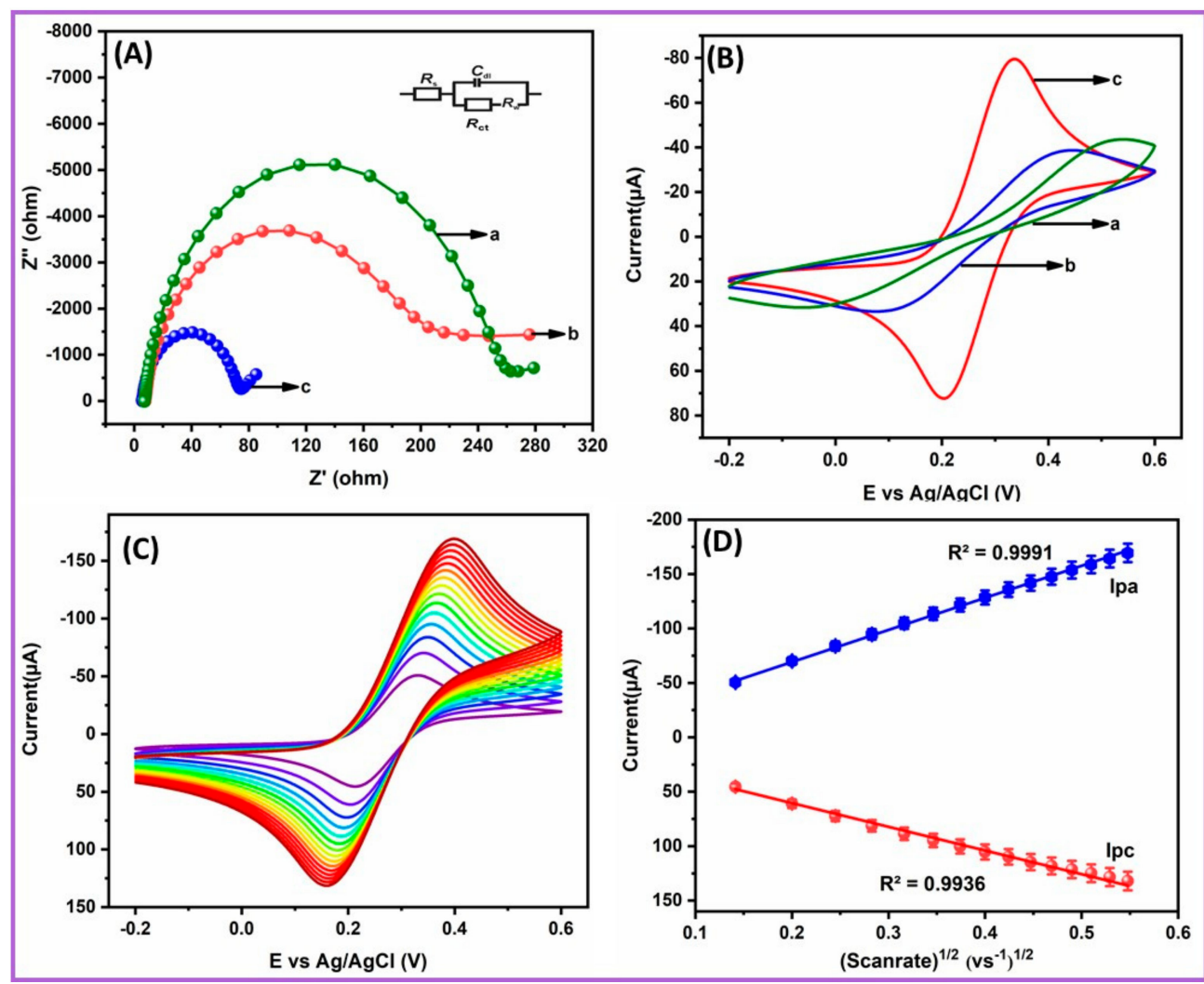

Figure 4. (A) EIS and (B) cyclic voltammetry (CV's) (a) of unmodified electrode, (b) $\mathrm{NiCo}_{2} \mathrm{O}_{4}-\mathrm{MFs} / \mathrm{GCE}$ and (c) $\mathrm{NiCO}_{2} \mathrm{~S}_{4}$-Ms/GCE in $0.1-\mathrm{M} \mathrm{KCl}$ containing $0.05 \mathrm{M}$ of $\left[\mathrm{Fe}(\mathrm{CN})_{6}\right]^{-3 /-4}$. (C) Scan rate of the nanocomposite modified electrode. (D) Calibration plot of $\left(v \text { vs. } \mathrm{Vs}^{-1}\right)^{1 / 2}$.

In addition, the cyclic voltammetry (CV's) were performed to investigate the electrochemical behavior of bare GCE (a), $\mathrm{NiCo}_{2} \mathrm{O}_{4}-\mathrm{MFs} / \mathrm{GCE}$ (b) and $\mathrm{NiCo}_{2} \mathrm{~S}_{4}-\mathrm{Ms} / \mathrm{GCE}$ (c) in 0.1-M KCl containing $0.05 \mathrm{M}$ of $\left[\mathrm{Fe}(\mathrm{CN})_{6}\right]^{-3 /-4}$ solution. In Figure $4 \mathrm{~B}$ as can be seen that, the highest reduction and reduction peak current and lower peak-to-peak separation ( $\triangle \mathrm{Ep}$ ) value of $89.24 \mathrm{mV}$ were observed for the $\mathrm{NiCo}_{2} \mathrm{~S}_{4}$-Ms/GCE. Moreover, the peak-to-peak separation ( $\triangle \mathrm{Ep}$ ) of unmodified electrode (a) and $\mathrm{NiCo}_{2} \mathrm{O}_{4}$-MFs/GCE (b) were measured to be 189.51 and $145.36 \mathrm{mV}$, respectively. Figure 4C shows the different scan rates at $\mathrm{NiCo}_{2} \mathrm{~S}_{4}-\mathrm{Ms} / \mathrm{GCE}$, in which the redox peak current increased consistently and their linear relationship with the square root of scan rates were plotted as shown in Figure 4D. Furthermore, the electrochemical active surface area value was measured based on the Randel's Sevcik equation (I). The electrochemical active surface area of bare GCE (a), $\mathrm{NiCO}_{2} \mathrm{O}_{4}-\mathrm{MFs} / \mathrm{GCE}$ (b) and $\mathrm{NiCO}_{2} \mathrm{~S}_{4}-\mathrm{Ms} / \mathrm{GCE}$ were calculated to be $0.082,0.102$ and $0.161 \mathrm{~cm}^{2}$, respectively. The results indicate the combination of bimetallic sulfides increased the surface area and showed excellent electrochemical contact between the surface of electrode and electrolyte solution.

$$
\mathrm{Ip}=2.69 \times 10^{5} \mathrm{n}^{3 / 2} \mathrm{AD}^{1 / 2} \mathrm{Cv}^{1 / 2}
$$

\subsection{Electrochemical Activity and Different $\mathrm{pH}$ at $\mathrm{NiCO}_{2} \mathrm{~S}_{4}-\mathrm{Ms} / \mathrm{GCE}$}

As shown in Figure 5A, the CV's with different electrodes, bare GCE (a), $\mathrm{NiCo}_{2} \mathrm{O}_{4}-\mathrm{MFs} / \mathrm{GCE}(\mathrm{b})$ and $\mathrm{NiCo}_{2} \mathrm{~S}_{4}-\mathrm{Ms} / \mathrm{GCE}$ (c) were recorded in $0.1 \mathrm{M}$ of phosphate buffer solution (PB) pH 7 containing $100-\mu \mathrm{M} 4-\mathrm{NQO}$ with the fixed scan rate of $0.05 \mathrm{~V} / \mathrm{s}$. The lower reduction peak current exhibited an unmodified GCE, which suggest the poor conductivity on the electrode surface. Furthermore, when the electrode was modified with $\mathrm{NiCO}_{2} \mathrm{O}_{4}-\mathrm{MFs} / \mathrm{GCE}$ there was a drastically increase in the current. The excellent peak current of $-26 \mu \mathrm{A}$ with the minimized reduction potential of $-0.29 \mathrm{~V}$ was noted on $\mathrm{NiCo}_{2} \mathrm{~S}_{4}-\mathrm{Ms} / \mathrm{GCE}$, which suggest that the larger surface area of $\mathrm{NiCo}_{2} \mathrm{~S}_{4}-\mathrm{Ms}$ can considerably enhance 
the sensitivity of the electrode. Moreover, the probable electrochemical reduction mechanism of 4-NQO on $\mathrm{NiCo}_{2} \mathrm{~S}_{4}-\mathrm{Ms} / \mathrm{GCE}$ are shown in Figure 6. Typically, 4-nitroquinoline n-oxide is irreversibly reduced to form 4-hydroxyaminoquinoline n-oxide. After this, the oxidation of 4-hydroxyaminoquinoline n-oxide occurs, which is subsequently reduced to 4-nitrosoquinoline n-oxide at the increasing scan. The accumulation time is one of the important parameters in electrochemical sensors to improve the sensitivity. Therefore, the accumulation time of the proposed sensor was studied in $0.1-\mathrm{M} \mathrm{pH} 7$ containing $100-\mu \mathrm{M} 4-\mathrm{NQO}$ using the $\mathrm{CV}$ technique and the corresponding current response versus time were plotted as shown in Figure S2. The obtained results indicate that the reduction peak increased with the increasing accumulation time. However, the accumulation time exceeds $20 \mathrm{~s}$, the reduction peak current of 4-NQO decreased. This was due to the adsorption taken at the surface of the electrode, which may have resisted the active site of the $\mathrm{NiCo}_{2} \mathrm{~S}_{4}-\mathrm{Ms}$ and the surface reached its saturation point at $20 \mathrm{~s}$. Thus, the optimal accumulation time of $20 \mathrm{~s}$ was preferred to achieve the high sensitivity for the proposed sensor.

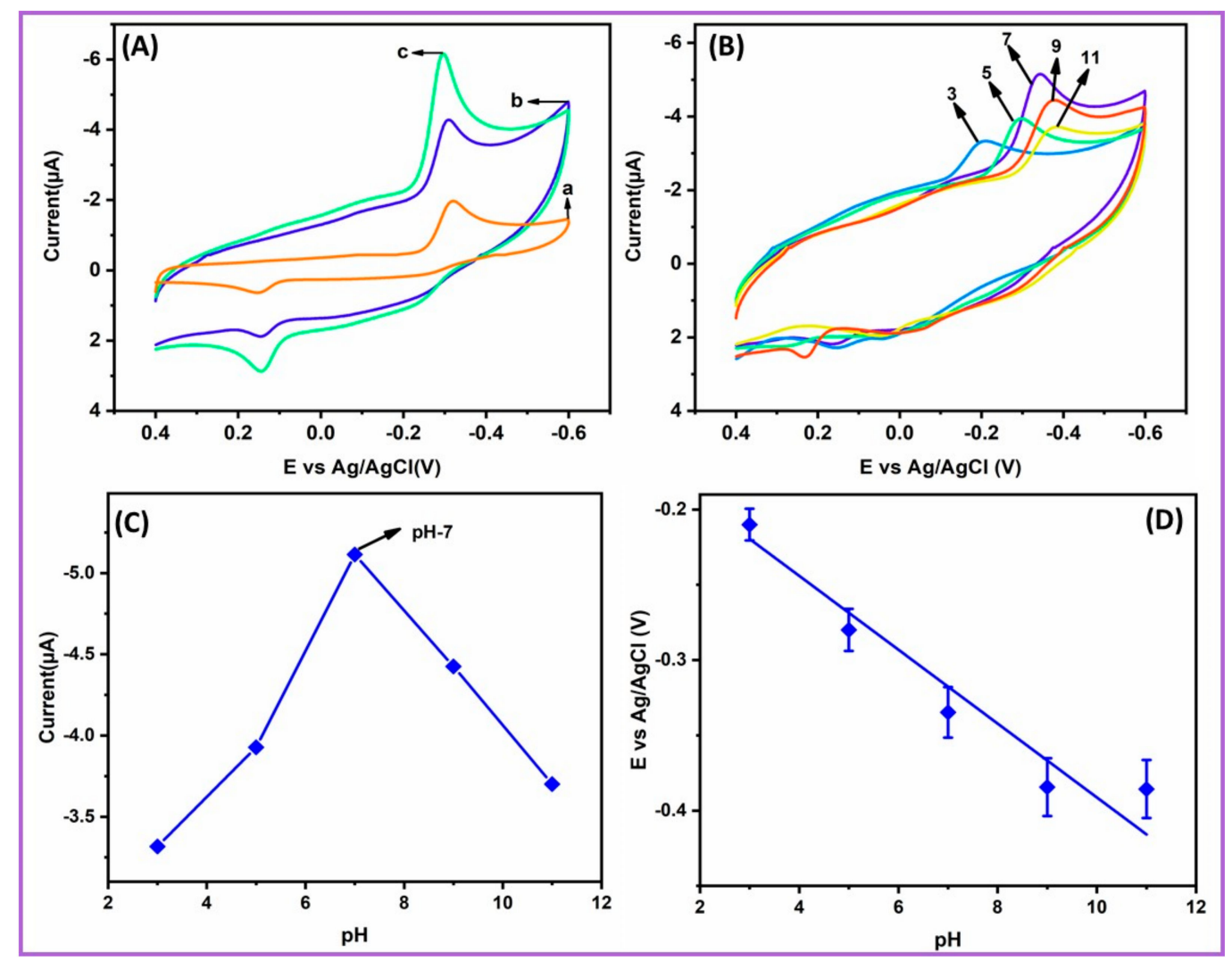

Figure 5. (A)-(a) CV's of unmodified glass carbon electrode (GCE), (b) $\mathrm{NiCo}_{2} \mathrm{O}_{4}-\mathrm{MFs} / \mathrm{GCE}$, and (c) $\mathrm{NiCo}_{2} \mathrm{~S}_{4}-\mathrm{Ms} / \mathrm{GCE}$ in 0.1-M pH 7 containing 100- $\mu \mathrm{M}$ 4-NQO. (B) CV's obtained at $\mathrm{NiCo}_{2} \mathrm{~S}_{4}-\mathrm{Ms} / \mathrm{GCE}$ for the varied $\mathrm{pH}$ from (3 to 11) containing 100- $\mu \mathrm{M} 4-\mathrm{NQO}$. (C) The plot current ( $\mu \mathrm{A})$ versus $\mathrm{pH}$ and (D) potential versus $\mathrm{pH}$. 


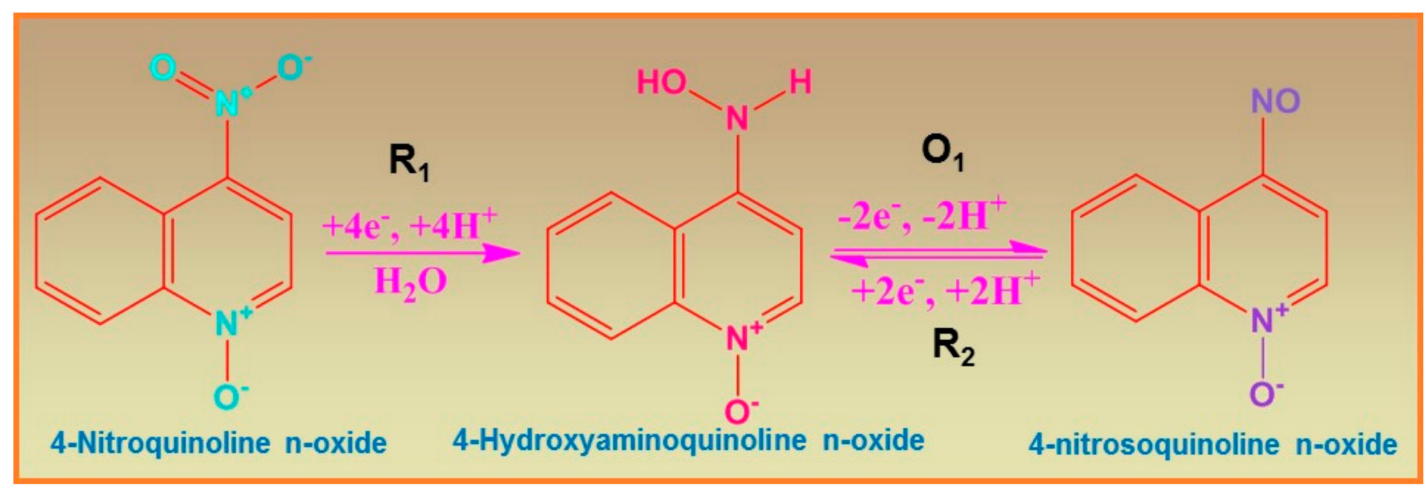

Figure 6. Possible reduction mechanism of 4-NQO at $\mathrm{NiCo}_{2} \mathrm{~S}_{4}-\mathrm{Ms} / \mathrm{GCE}$.

Furthermore, the influence of $\mathrm{pH}$ at $\mathrm{NiCO}_{2} \mathrm{~S}_{4}-\mathrm{Ms} / \mathrm{GCE}$ for the detection of 4-NQO was investigated by varying the $\mathrm{PB} \mathrm{pH}$ from 3 to 11 at a fixed scan rate of $0.05 \mathrm{Vs}^{-1}$. Figure $5 \mathrm{~B}$ displays the $\mathrm{CV}^{\prime} \mathrm{s}$ curves of different $\mathrm{pH} 3$ to 11 containing 100- $\mu \mathrm{M}$ 4-NQO. The well-shaped peak with higher reduction peak current of $-5.29 \mu \mathrm{A}$ was noted at $\mathrm{pH} 7$ Figure $5 \mathrm{C}$. At some point, the peak current started to decrease, which indicates that the biomolecules reached its maximum $\mathrm{pH}$ value of 9-11. Hence, the $\mathrm{pH} 7$ was chosen as the enhanced $\mathrm{pH}$ for the reduction of 4-NQO. In addition, the plot between the reduction peak potential and $\mathrm{pH}$ were plotted as shown in Figure 5D, which was linear, and its regression equation were represented as $E_{p}(V)=-0.056 \mathrm{pH}-0.624$. The obtained slope value of $-56 \mathrm{mV} / \mathrm{pH}$ indicates that the reaction was equal number of proton and electron transferred.

\subsection{Influence of Different Concentration and Scan Rate}

In addition, the influence of various concentration of 4-NQO at as-prepared $\mathrm{NiCO}_{2} \mathrm{~S}_{4}-\mathrm{Ms} / \mathrm{GCE}$ were analyzed in $0.1-\mathrm{M} \mathrm{pH} 7$ at fixed scan window of $0.05 \mathrm{Vs}^{-1}$. As shown in Figure $7 \mathrm{~A}$, the $\mathrm{CV}$ curve were recorded for the increasing concentration of 4-NQO. For every sequential addition of 4-NQO from 25 to $250 \mu \mathrm{M}$ the reduction peak current also increased linearly. Finally, the linear relationship of reduction peak current versus the concentration of 4-NQO were plotted as Figure 7B. Moreover, the regression equation is written to be $y=0.0253 \mathrm{x}+2.2034$ with the correlation coefficient of $R^{2}=0.9938$. The obtained results confirm that, the as-prepared $\mathrm{NiCo}_{2} \mathrm{~S}_{4}-\mathrm{Ms}$ is a promising electrode material for the rapid detection of 4-NQO without fouling. 

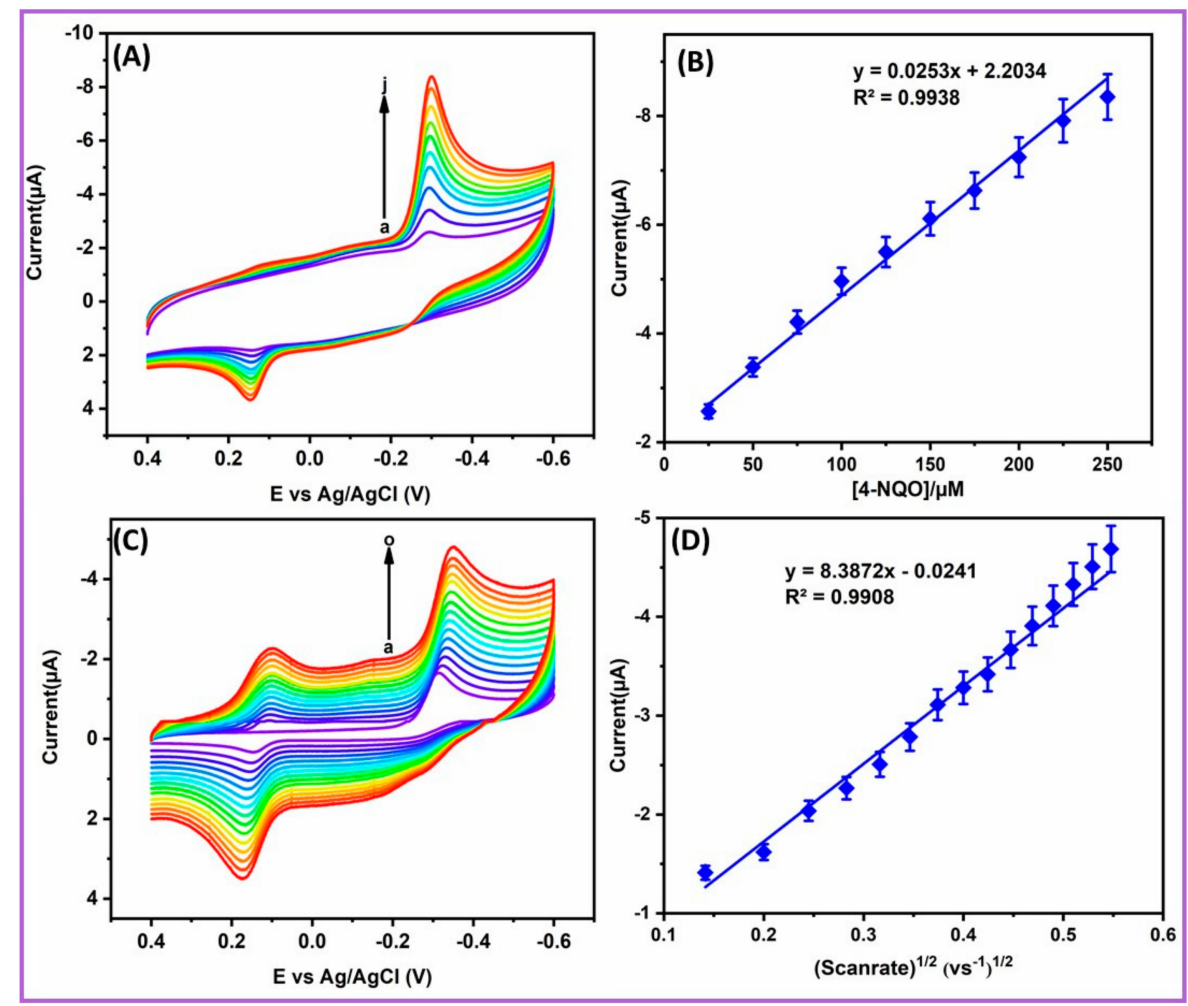

Figure 7. (A) CVs obtained at different concentration of 4-NQO (a-j 25-250 $\mu \mathrm{M})$ and (B) Linear relationship between the current $(\mu \mathrm{A})$ and 4-NQO concentration. $(C) C V s$ attained for the different scan rate (a-o 20 to $300 \mathrm{mVs}^{-1}$ ) in $0.1-\mathrm{M} \mathrm{pH} 7$ at $\mathrm{NiCo}_{2} \mathrm{~S}_{4}$-Ms/GCE. (D) Calibration plot of the cathodic peak current and scan rates.

In order to study the effects of scan rates at $\mathrm{NiCo}_{2} \mathrm{~S}_{4}-\mathrm{Ms} / \mathrm{GCE}$ was investigated by $\mathrm{CV}$ techniques. Figure $7 \mathrm{C}$, indicates the CVs of different scant rates from 20 to $300 \mathrm{mVs}^{-1}$ in $0.1-\mathrm{M} \mathrm{PB} \mathrm{pH} 7$ contains $100-\mu \mathrm{M} 4-\mathrm{NQO}$.With consistently increasing scan rates, there was a linear increase in the cathodic peak current. Figure 7D shows the linear relationship between the cathodic peak current of 4-NQO versus square root of the scan rates. In addition, the regression equation was calculated to be $y=8.3872 \mathrm{x}$ - 0.0241 with the correlation coefficient of $R^{2}=0.9908$, which indicates that reduction of 4-NQO at $\mathrm{NiCo}_{2} \mathrm{~S}_{4}-\mathrm{Ms} / \mathrm{GCE}$ was a diffusion-controlled process.

\subsection{DPV Analysis of 4-NQO Ions at $\mathrm{NiCO}_{2} \mathrm{~S}_{4}-\mathrm{Ms} / \mathrm{GCE}$ Techniques}

Differential pulse voltammetry common techniques were used to measure the essential electrochemical parameters such as linear range, sensitivity and limit of detection (LOD). Hence, the DPV technique was used to detect the 4-NQO at $\mathrm{NiCo}_{2} \mathrm{~S}_{4}-\mathrm{Ms} / \mathrm{GCE}$ in $0.1-\mathrm{M} \mathrm{pH} 7$ at a fixed potential of 0.4 to $-0.6 \mathrm{~V}$. Figure $8 \mathrm{~A}$ displays the DPV curve of increasing concentration of 4-NQO. The obtained results indicate the reduction peak current increased with increasing concentration of 4-NQO. The $\mathrm{NiCO}_{2} \mathrm{~S}_{4}-\mathrm{Ms} / \mathrm{GCE}$ modified electrode showed an excellent linear relationship between the reduction peak current and the concentration of 4-NQO, which were plotted as shown in Figure 8B. Moreover, the linear regression equation was calculated to be $i \mathrm{p}_{\mathrm{a}}(\mu \mathrm{A})=0.4014 \mu \mathrm{M}-0.0153\left(R^{2}=0.9985\right)$. Wherein, the $\mathrm{NiCo}_{2} \mathrm{~S}_{4}$-Ms/GCE shows the wider range of 0.005 to $596.64-\mu \mathrm{M} 4-\mathrm{NQO}$. In addition, the LOD of the as-prepared sensor was measured using the standard formula of LOD $=3 \sigma / S$, where the $\sigma$ and $S$, is the standard deviation and slope of the curve, respectively. Moreover, the LOD of $\mathrm{NiCo}_{2} \mathrm{~S}_{4}-\mathrm{Ms} / \mathrm{GCE}$ for the detection of 4-NQO were measured to be $2.29 \mathrm{nM}$. Moreover, the proposed sensor wes compared with previously reported 4-NQO sensor as the results as-prepared $\mathrm{NiCo}_{2} \mathrm{~S}_{4}-\mathrm{Ms} / \mathrm{GCE}$ shows the very low detection limit Table 1. Thus, it is a promising electrode material for the detection of 4-NQO. 


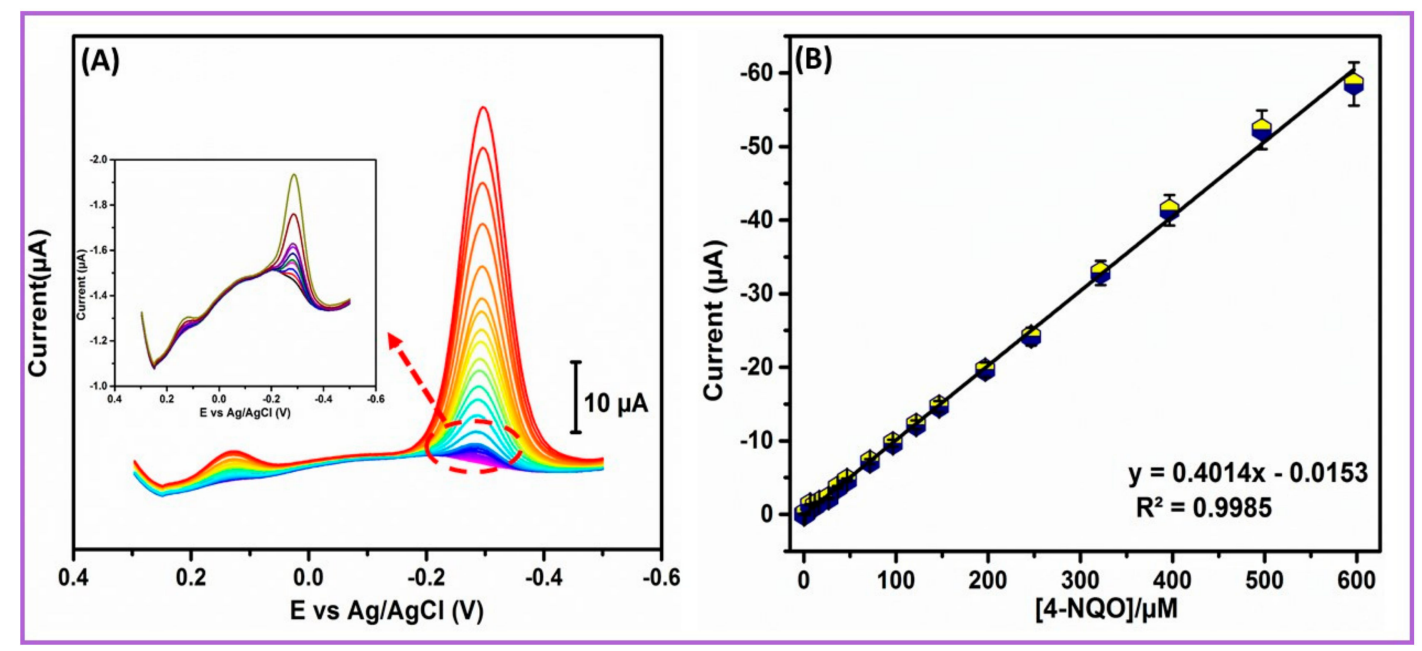

Figure 8. (A) DPV response of the different concentration of 4-NQO; (B) linear response of the reduction peak current versus concentration of 4-NQO.

Table 1. Comparison of as-prepared sensor with the other previously reported 4-NQO sensor.

\begin{tabular}{cccc}
\hline Method & Linear Range $(\mu \mathbf{M})$ & LOD $(\mathbf{n M})$ & Ref \\
\hline $\mathrm{Bi}_{2} \mathrm{WO}_{6} / \mathrm{rGOs} \cdot \mathrm{NC} /{ }^{\mathrm{a}} \mathrm{GCE} /{ }^{\mathrm{b}}$ it & $0.025-718$ & 6.11 & {$[22]$} \\
$\mathrm{Fe}_{2} \mathrm{~N} \cdot \mathrm{NPs}_{\mathrm{r} G \mathrm{rGS} /{ }^{\mathrm{c}} \mathrm{SPCE} /{ }^{\mathrm{d}} \mathrm{DPV}}$ & $0.05-574.2$ & 9.24 & {$[16]$} \\
$\mathrm{ZnFe}_{2} \mathrm{O}_{4} \cdot \mathrm{NCs} / \mathrm{rGO} /{ }^{\mathrm{a}} \mathrm{GCE} /{ }^{\mathrm{d}} \mathrm{DPV}$ & $0.025-534.12$ & 8.27 & {$[19]$} \\
$\mathrm{e}$ & - & 0.157 & {$[29]$} \\
$\mathrm{NiCo}_{2} \mathrm{~S}_{4}-\mathrm{Ms} / \mathrm{GCE} / \mathrm{DPV}$ & $0.005-596.64$ & 2.29 & This work \\
\hline
\end{tabular}

a Glassy carbon electrode; ${ }^{b}$ (i-t) amperometric; ${ }^{\mathrm{c}}$ screen printed carbon electrode; ${ }^{\mathrm{d}}$ differential pulse voltammetry;

e high-performance liquid chromatography.

\subsection{Interference and Stability Studies of $\mathrm{NiCO}_{2} \mathrm{~S}_{4}-\mathrm{Ms} / \mathrm{GCE}$}

Selectivity and stability are the most considered parameter in electrochemical studies. Hence, the selectivity of the sensor was examined using $\mathrm{NiCo}_{2} \mathrm{~S}_{4}-\mathrm{Ms} / \mathrm{GCE}$ with 4-NQO, as well as in the presence of possible bioactive and nitro compounds. The selectivity of the prepared sensor was studied using DPV techniques. The DPV results of the $\mathrm{NiCo}_{2} \mathrm{~S}_{4}-\mathrm{Ms} / \mathrm{GCE}$ in presence of $0.5 \mu \mathrm{M} 4-\mathrm{NQO}$ and $0.7 \mu \mathrm{M}$ possible interferents such as 3-nitro-l-tryosine (3-NT), 4-nitrophenol (4-NP), chloramphenicol $(\mathrm{CAP})$, nitro benzene $(\mathrm{NB})$ and continued addition of $1.5 \mu \mathrm{M}$ common biologic analytes glucose (Glu), ascorbic acid (AA), hydrogen peroxide $\left(\mathrm{H}_{2} \mathrm{O}_{2}\right)$ and dopamine (DA) are shown in Figure S3. The related nitro compounds such as 3-NT, 4-NP, NB, CAP showed minor interference with the 4-NQO due to structural similarity. However, the corresponding relative error was found less than $7 \%$ as shown in Figure 9A. Notably, most of the other nitro compounds show their reduction peaks at high overpotential of -0.50 to $-0.60 \mathrm{~V}$, which is far from the reduction potential of $4-\mathrm{NQO}$. In other words, although all these compounds have nitro groups, they require different energy to be reduced, which provides the electrode a good selectivity. Approximately three-fold excess concentrations of Glu, AA, $\mathrm{H}_{2} \mathrm{O}_{2}$ and DA did not show any significant interference, indicating that the method is selective in biologic samples. Moreover, the working stability of $\mathrm{NiCo}_{2} \mathrm{~S}_{4}-\mathrm{Ms} / \mathrm{GCE}$ were examined using the DPV technique. Figure 9B shows the stability current response of the prepared sensor in $0.1 \mathrm{M} \mathrm{pH}$ 7 containing $10-\mu \mathrm{M} 4-\mathrm{NQO}$. After 15 days usage, the sensor maintained a stability of $94.59 \%$. Thus, the stability test of the $\mathrm{NiCo}_{2} \mathrm{~S}_{4}-\mathrm{Ms} / \mathrm{GCE}$ confirms the outstanding working stability for the detection of 4-NQO. 


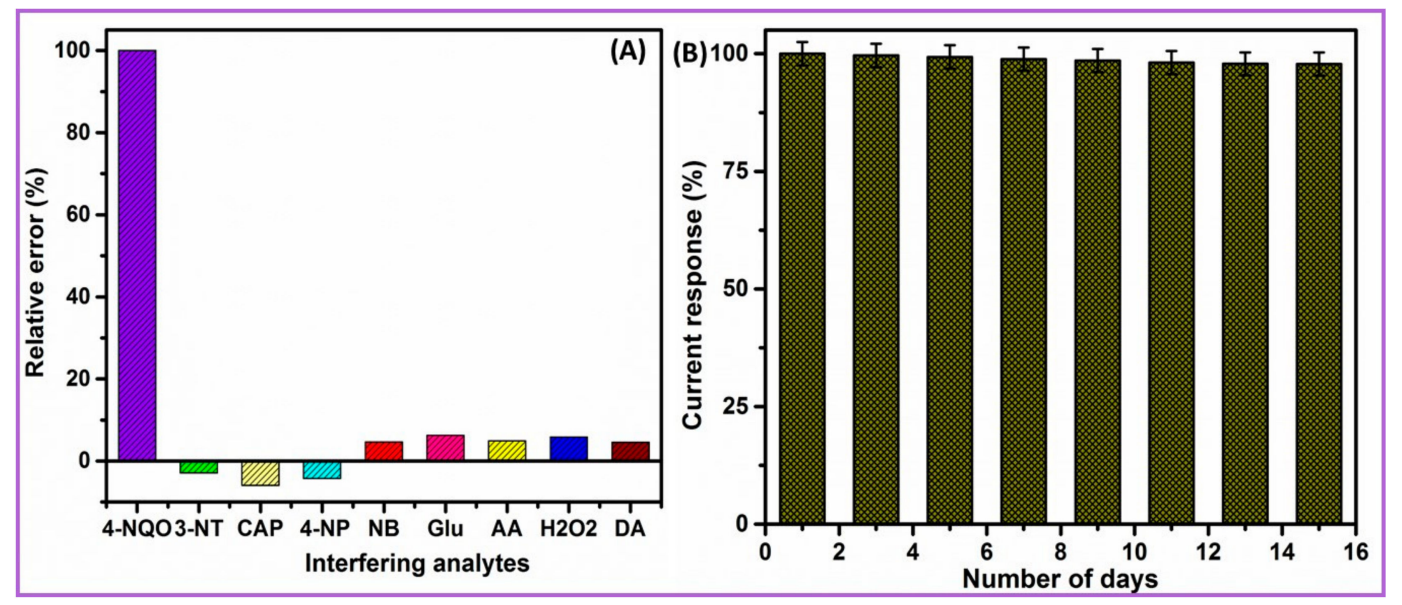

Figure 9. (A) Influence of interfering ions in $0.1-\mathrm{M} \mathrm{pH} 7$ containing $0.5 \mu \mathrm{M}$ of 4 -NQO and higher concentration of interfering analytes; (B) stability plot of $\mathrm{NiCo}_{2} \mathrm{~S}_{4}-\mathrm{Ms} / \mathrm{GCE}$ of its usage for 15 days.

\subsection{Real Sample Analysis}

The practical applicability of prepared sensor was examined in the biologic sample human blood serum and saliva samples. The preparation of biologic samples was diluted with buffer solution and the known concentration of 4-NQO were spiked. Finally, DPV techniques were carried out for the prepared real samples. Fascinatingly, the blood serum and saliva samples were showed outstanding found and recovery rates, which are tabulated in Table 2 . At the end, the prepared $\mathrm{NiCo}_{2} \mathrm{~S}_{4}-\mathrm{Ms} / \mathrm{GCE}$ established as the effective electrode for the real time applicability.

Table 2. Determination of 4-NQO in biologic samples at $\mathrm{NiCo}_{2} \mathrm{~S}_{4}-\mathrm{Ms} / \mathrm{GCE}$ modified electrode.

\begin{tabular}{ccccc}
\hline Real Samples & Added/nM & Found/nM & Recovery/\% & ${ }^{*}$ RSD/\% \\
\hline \multirow{2}{*}{ Human blood serum } & 50 & 47.58 & 95.16 & 2.45 \\
& 100 & 96.48 & 96.48 & 2.81 \\
\hline \multirow{2}{*}{ Saliva } & 50 & 49.12 & 98.24 & 2.56 \\
& 100 & 94.29 & 94.29 & 2.76 \\
\hline
\end{tabular}

* Related standard deviation (RSD) of $n=3$.

\section{Experimental Section}

\subsection{Synthesis Method for $\mathrm{NiCo}_{2} \mathrm{~S}_{4}-\mathrm{Ms}$ and $\mathrm{NiCo}_{2} \mathrm{O}_{4}-\mathrm{MFs}$}

All chemicals were purchased from Sigma-Aldrich in analytical grade and used without any further purification. The details of chemical purchases, preparation methods of buffer solutions and instrumentation techniques are detailed in the supplementary data (S1). The $\mathrm{NiCo}_{2} \mathrm{O}_{4}-\mathrm{MFs}$ and $\mathrm{NiC}_{2} \mathrm{~S}_{4}$-Ms were synthesized by the hydrothermal method. Briefly, a 1:2 molar ratio of $\mathrm{Ni}\left(\mathrm{CH}_{3} \mathrm{COO}\right)_{2} \cdot 4 \mathrm{H}_{2} \mathrm{O}$ and $\mathrm{Co}\left(\mathrm{CH}_{3} \mathrm{COO}\right)_{2} \cdot 4 \mathrm{H}_{2} \mathrm{O}$ were thoroughly dissolved in $50 \mathrm{~mL}$ of $\mathrm{C}_{2} \mathrm{H}_{6} \mathrm{O}_{2}$ under magnetic stirring for $30 \mathrm{~min}$. Then the mixture was carefully transferred into a $100 \mathrm{~mL}$ Teflon-lined stainless-steel autoclave and maintained for $180^{\circ} \mathrm{C}$ for $12 \mathrm{~h}$ in a hydrothermal oven. After $12 \mathrm{~h}$, the reaction mixture was allowed to cool room temperature and centrifuged with water and ethanol to collect the $\mathrm{NiCo}_{2} \mathrm{O}_{4}$-MFs precipitate. Finally, the collected precipitate was dried in air at 80 ${ }^{\circ} \mathrm{C}$ for $10 \mathrm{~h}$ [30]. To synthesis, the $\mathrm{NiCo}_{2} \mathrm{~S}_{4}-\mathrm{Ms}$, a $1: 2$ molar ratio of the $\mathrm{NiSO}_{4} \cdot 6 \mathrm{H}_{2} \mathrm{O}$ and $\mathrm{CoSO}_{4} \cdot 7 \mathrm{H}_{2} \mathrm{O}$ were dissolved in $0.5 \mathrm{M} \mathrm{Na}_{2} \mathrm{~S} \cdot 5 \mathrm{H}_{2} \mathrm{O}$. Then the same procedure was followed to obtain the $\mathrm{NiCo}_{2} \mathrm{~S}_{4}-\mathrm{Ms}$ (Scheme 1). 


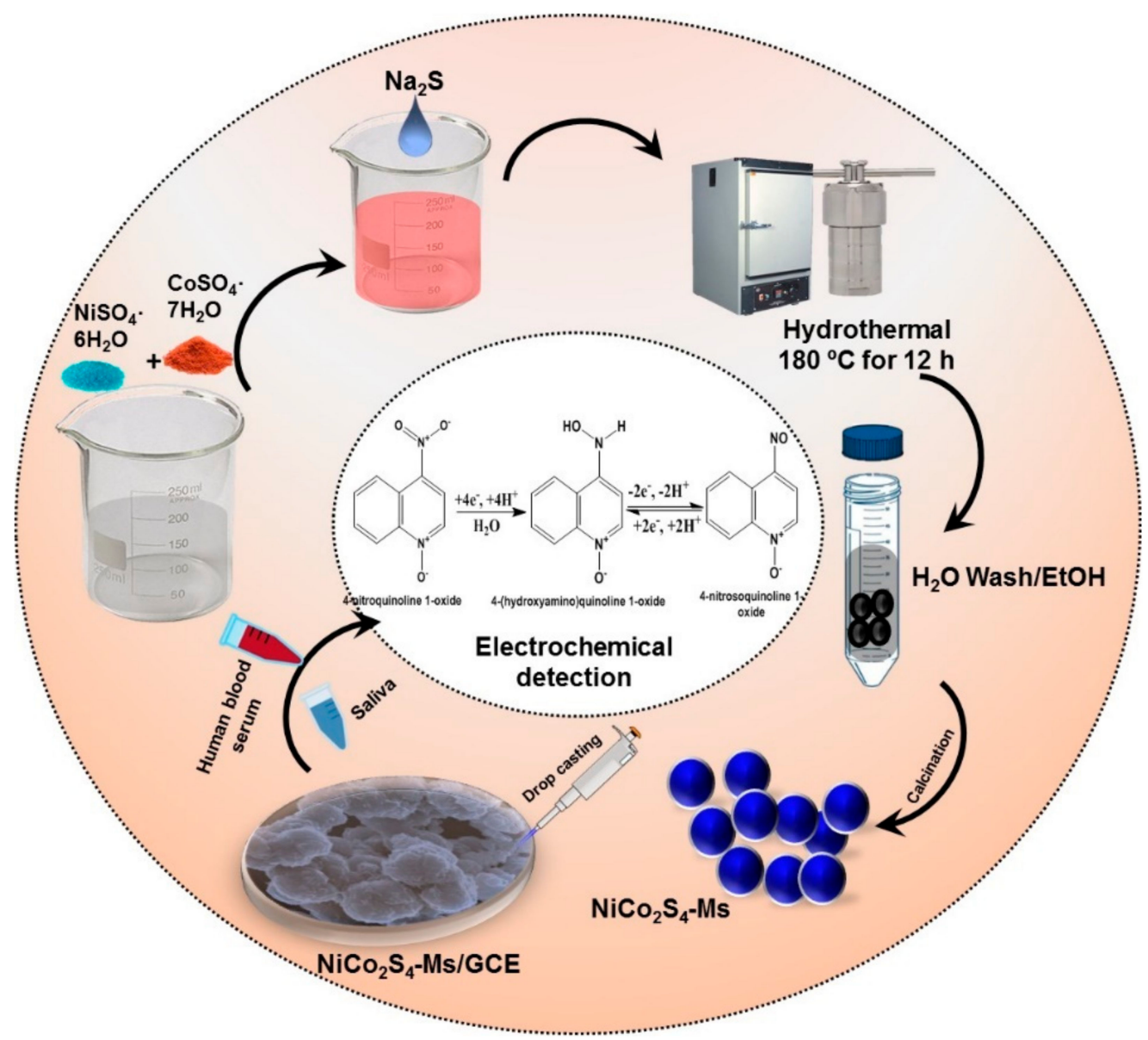

Scheme 1. Synthesis methodology of $\mathrm{NiCO}_{2} \mathrm{~S}_{4}$-Ms and its electrocatalytic properties for the detection of 4-nitroquinoline n-oxide.

\subsection{Fabrication of $\mathrm{NiCO}_{2} \mathrm{~S}_{4}-\mathrm{Ms}$ Modified GCE}

The surface of GCE was cleaned by $0.5 \mathrm{mg}$ of alum in a slurry. Then the GCE was dipped into an ethanol solution and sonicated for $10 \mathrm{~min}$. After this, the GCE was pre-cleaned by cycling between -0.8 to $0.8 \mathrm{~V}$ in $\mathrm{PB} \mathrm{pH} 7$ for the 25 continuous cycle. Then, $1 \mathrm{mg}$ of as-prepared $\mathrm{NiCo}_{2} \mathrm{~S}_{4}-\mathrm{Ms}$ was dispersed in $1 \mathrm{~mL}$ of ethanol and sonicated for $20 \mathrm{~min}$. Approximately $6 \mu \mathrm{L}$ of $\mathrm{NiCo}_{2} \mathrm{~S}_{4}-\mathrm{Ms}_{\text {s suspension }}$ was drop-cast on the surface of GCE and dried in a $50{ }^{\circ} \mathrm{C}$ oven. Finally, the as-prepared $\mathrm{NiCo}_{2} \mathrm{~S}_{4}-\mathrm{Ms}$ modified GCE was used for the electrochemical characterization.

\section{Materials and Reagents}

Nickel acetate $\mathrm{Ni}\left(\mathrm{CH}_{3} \mathrm{COO}\right)_{2} \cdot 4 \mathrm{H}_{2} \mathrm{O}$, cobalt acetate $\mathrm{Co}\left(\mathrm{CH}_{3} \mathrm{COO}\right)_{2} \cdot 4 \mathrm{H}_{2} \mathrm{O}$, ammonium hydroxide $\left(\mathrm{NH}_{4} \mathrm{OH}\right)$, nickel sulfate $\mathrm{NiSO}_{4} \cdot 6 \mathrm{H}_{2} \mathrm{O}$, cobalt sulfate $\mathrm{CoSO}_{4} \cdot 7 \mathrm{H}_{2} \mathrm{O}$, 4-nitroquinoline n-oxide, uric acid (UA), ascorbic acid (AA), dopamine (DA), glucose (GLU), 3-nitrotyrosine (3-NT), L-cysteine and $\mathrm{H}_{2} \mathrm{O}_{2}$ and all other chemicals were purchased from Sigma-Aldrich and used as received. Double-distilled water was used for all the experiments. 0.1-M phosphate buffer (PB) ( $\mathrm{pH}$ 7.0) prepared from sodium dihydrogen phosphate and disodium hydrogen phosphate was used as supporting electrolyte. Human blood serum and saliva samples were acquired from Chang Gung Medical Hospital, Taoyuan, Taiwan. The research protocols of human blood serum and saliva samples experiments were followed as per the laws and institutional guidelines of Chang Gung Medical Hospital (CGMH), Taiwan. 


\section{Methods}

The surface modification of the as-formed composite was examined using field emission scanning electron microscope (FESEM-JEOL-7600F, Jeol instruments, Musashino, Akishima, Tokyo, Japan): Ingredients of the elemental composition and elemental mapping were analyzed by energy-dispersive X-ray spectroscopy (EDX) with HORIBA EMAX X-ACT (Horiba instruments, AkzoNobel House, Singapore). The quantitative analysis and defects and disordered nature of the as-prepared composite were investigated by PerkinElmer PHI-5702 (PerkinElmer Inc., Waltham, MA, USA).

The crystalline nature of the composite was examined by XRD, XPERT-PRO spectrometer (Malvern Panalytical B.V., Almelose Aa, Netherland). The electrochemical properties and electrocatalytic activity were examined using electrochemical impedance spectroscopy (EIS) and cyclic voltammetry (CV); i-t amperometry was carried out CHI 1205A (CH instruments, Inc. Austin, TX, USA). The CHI instrument consists of a three-electrode system, in which the platinum wire and $\mathrm{Ag} / \mathrm{AgCl}$ (sat. $\mathrm{KCl}$ ) were used as auxiliary and reference electrodes, and a pre-washed GCE (glassy carbon electrode) acted as a working electrode.

\section{Conclusions}

In summary, we successfully synthesized $\mathrm{NiCO}_{2} \mathrm{~S}_{4}-\mathrm{Ms}$ and $\mathrm{NiCo}_{2} \mathrm{O}_{4}-\mathrm{MFs}$ through the hydrothermal method. The formation of $\mathrm{NiCo}_{2} \mathrm{~S}_{4}-\mathrm{Ms}$ and $\mathrm{NiCo}_{2} \mathrm{O}_{4}-\mathrm{MFs}$ were conformed through the several analytical techniques such as FESEM, EDX, XPS and XRD. Further, the as-prepared nanocomposites were used as electrode materials for the detection of 4-NQO. Fascinatingly, the $\mathrm{NiCO}_{2} \mathrm{~S}_{4}$-Ms modified electrode showed excellent electrochemical performances such as a wider range, low limit detection, higher selectivity and outstanding stability for the detection of 4-NQO. In addition, the practical applicability of the as-prepared nanocomposite were scrutinized in the human blood serum and saliva samples, which showed good recovery for both samples. To our knowledge, the hydrothermally synthesized $\mathrm{NiCo}_{2} \mathrm{~S}_{4}-\mathrm{Ms}$ is the one of the most effective electrocatalysts for the detection of 4-NQO.

Supplementary Materials: The following are available online at http:/www.mdpi.com/1422-0067/21/9/3273/s1, Figure S1. Mapping image of NiCo2O4-MFs (A). (B-D) conforms the presence of Ni (B), Co (C), O (D). (E) EDX profile for NiCo2O4-MFs; Figure S2. Effect of accumulation time on the reduction peak current of $100 \mu \mathrm{M} 4-\mathrm{NQO}$ at NiCo2S4-MS/GCE; Figure S3. DPV curve of obtained at NiCo2S4-Ms/GCE in the $0.1 \mathrm{M} \mathrm{pH}-7$ containing $0.5 \mu \mathrm{M}$ of 4-NQO with other bioactive and electro active nitro species.

Author Contributions: T.-W.C. and E.T. developed the theory and performed the computations and carried out the analytical techniques. S.-M.C. and X.L. helped supervise the project, finical support and helped to written the draft manuscript M.A. and S.M. performed the analytic calculations and performed the numerical simulations. All authors have read and agreed to the published version of the manuscript.

Funding: This project was supported by the Ministry of Science and Technology (MOST 107-2113-M-027 -005-MY3), Taiwan (ROC). This work also jointly supported by the projects from NTUT-NUST-109-01 and NSFC51872141, National Taipei University of Technology and Nanjing University of Science and Technology.

Conflicts of Interest: The authors declare that there is no conflict of interest.

\section{References}

1. Kim, J.-H.; Kang, S.H.; Zhu, K.; Kim, J.Y.; Neale, N.R.; Frank, A.J. Ni-NiO core-shell inverse opal electrodes for supercapacitors. Chem. Commun. 2011, 47, 5214. [CrossRef] [PubMed]

2. Yang, L.; Cheng, S.; Ding, Y.; Zhu, X.; Wang, Z.L.; Liu, M. Hierarchical Network Architectures of Carbon Fiber Paper Supported Cobalt Oxide Nanonet for High-Capacity Pseudocapacitors. Nano Lett. 2011, 12, 321-325. [CrossRef] [PubMed]

3. Sun, M.; Tie, J.; Cheng, G.; Lin, T.; Peng, S.; Deng, F.; Ye, F.; Yu, L. In situ growth of burl-like nickel cobalt sulfide on carbon fibers as high-performance supercapacitors. J. Mater. Chem. A 2015, 3, 1730-1736. [CrossRef]

4. An, W.; Liu, L.; Gao, Y. Ni 0.9 Co 1.92 Se 4 nanostructures: Binder-free electrode of coral-like bimetallic selenide for supercapacitors. RSC Adv. 2016, 6, 75251-75257. [CrossRef] 
5. Chen, H.C.; Jiang, J.; Zhang, L.; Qi, T.; Xia, D.; Wan, H. Facilely synthesized porous NiCo2O4 flowerlike nanostructure for high-rate supercapacitors. J. Power Sources 2014, 248, 28-36. [CrossRef]

6. Zhou, Q.; Xing, J.; Gao, Y.; Lv, X.; He, Y.; Guo, Z.; Li, Y. Ordered Assembly of NiCo2O4Multiple Hierarchical Structures for High-Performance Pseudocapacitors. ACS Appl. Mater. Interfaces 2014, 6, 11394-11402. [CrossRef]

7. Li, L.; Yang, H.; Zhang, L.; Miao, J.; Sun, C.; Huang, W.; Dong, X.; Liu, B. Hierarchical carbon@Ni 3 S 2 @MoS 2 double core-shell nanorods for high-performance supercapacitors. J. Mater. Chem. A 2016, 4, 1319-1325. [CrossRef]

8. Shen, M.; Ruan, C.; Chen, Y.; Jiang, C.; Ai, K.; Lu, L. Covalent Entrapment of Cobalt-Iron Sulfides in N-Doped Mesoporous Carbon: Extraordinary Bifunctional Electrocatalysts for Oxygen Reduction and Evolution Reactions. ACS Appl. Mater. Interfaces 2015, 7, 1207-1218. [CrossRef]

9. Wang, X.; Shi, B.; Fang, Y.; Rong, F.; Huang, F.; Que, R.; Shao, M. High capacitance and rate capability of a Ni 3 S 2 @CdS core-shell nanostructure supercapacitor. J. Mater. Chem. A 2017, 5, 7165-7172. [CrossRef]

10. Ouyang, Y.; Ye, H.; Xia, X.; Jiao, X.; Li, G.; Mutahir, S.; Wang, L.; Mandler, D.; Lei, W.; Hao, Q.; et al. Hierarchical electrodes of NiCo2S4 nanosheets-anchored sulfur-doped $\mathrm{Co} 3 \mathrm{O} 4$ nanoneedles with advanced performance for battery-supercapacitor hybrid devices. J. Mater. Chem. A 2019, 7, 3228-3237. [CrossRef]

11. Yu, L.; Zhang, L.; Bin Wu, H.; Lou, X.W. (David) Formation of NixCo3-xS4Hollow Nanoprisms with Enhanced Pseudocapacitive Properties. Angew. Chem. Int. Ed. 2014, 53, 3711-3714. [CrossRef] [PubMed]

12. Pu, J.; Cui, F.; Chu, S.; Wang, T.; Sheng, E.; Wang, Z. Preparation and Electrochemical Characterization of Hollow Hexagonal NiCo2S4 Nanoplates as Pseudocapacitor Materials. ACS Sustain. Chem. Eng. 2013, 2, 809-815. [CrossRef]

13. Xiao, T.; Li, J.; Zhuang, X.; Zhang, W.; Wang, S.; Chen, X.; Xiang, P.; Jiang, L.; Tan, X. Wide potential window and high specific capacitance triggered via rough NiCo2S4 nanorod arrays with open top for symmetric supercapacitors. Electrochim. Acta 2018, 269, 397-404. [CrossRef]

14. Padmanathan, N.; Selladurai, S. In AIP Conference Proceeding: Sonochemically precipitated spinel Co[sub 3]O[sub 4] and $\mathrm{NiCo}[s u b 2] \mathrm{O}[\mathrm{sub} 4]$ nanostructures as an electrode materials for supercapacitor; AIP Publishing: Melville, NY, USA, 2013; pp. 1216-1217.

15. Elaiyappillai, E.; Akilarasan, M.; Chen, S.-M.; Kogularasu, S.; Johnson, P.M.; Tamilarasan, E.B. Sonochemically Recovered Aluminum Oxide Nanoparticles from Domestic Aluminum Wastes as a Highly Stable Electrocatalyst for Proton-Pump Inhibitor (Omeprazole) Detection. J. Electrochem. Soc. 2020, 167, 027544. [CrossRef]

16. Rajaji, U.; Muthumariappan, A.; Chen, S.-M.; Chen, T.-W.; Tseng, T.-W.; Wang, K.; Qi, D.; Jiang, J. Facile sonochemical synthesis of porous and hierarchical manganese(III) oxide tiny nanostructures for super sensitive electrocatalytic detection of antibiotic (chloramphenicol) in fresh milk. Ultrason. Sonochemistry 2019, 58, 104648. [CrossRef] [PubMed]

17. Pinjari, D.V.; Pandit, A.B. Room temperature synthesis of crystalline $\mathrm{CeO} 2$ nanopowder: Advantage of sonochemical method over conventional method. Ultrason. Sonochemistry 2011, 18, 1118-1123. [CrossRef]

18. Chen, S.-M.; Muthumariappan, A.; Chen, S.-M.; Chen, T.-W.; Ramalingam, R.J. A novel electrochemical sensor for the detection of oxidative stress and cancer biomarker (4-nitroquinoline N-oxide) based on iron nitride nanoparticles with multilayer reduced graphene nanosheets modified electrode. Sens. Actuators B: Chem. 2019, 291, 120-129. [CrossRef]

19. Chen, T.-W.; Rajaji, U.; Chen, S.-M.; Al Mogren, M.M.; Hochlaf, M.; Al Harbi, S.D.A.; Ramalingam, R.J. A novel nanocomposite with superior electrocatalytic activity: A magnetic property based $\mathrm{ZnFe} 2 \mathrm{O} 4$ nanocubes embellished with reduced graphene oxide by facile ultrasonic approach. Ultrason. Sonochemistry 2019, 57, 116-124. [CrossRef]

20. Nunoshiba, T.; Demple, B. Potent intracellular oxidative stress exerted by the carcinogen 4-nitroquinoline-N-oxide. Cancer Res. 1993, 53, 3250-3252.

21. Poot, M.; Gollahon, K.A.; Emond, M.J.; Silber, J.R.; Rabinovitch, P.S. Werner syndrome diploid fibroblasts are sensitive to 4-nitroquinoline-N-oxide and 8-methoxypsoralen: Implications for the disease phenotype. FASEB J. 2002, 16, 757-758. [CrossRef] 
22. Muthumariyappan, A.; Rajaji, U.; Chen, S.-M.; Chen, T.-W.; Li, Y.-L.; Ramalingam, R.J. One-pot sonochemical synthesis of Bi2WO6 nanospheres with multilayer reduced graphene nanosheets modified electrode as rapid electrochemical sensing platform for high sensitive detection of oxidative stress biomarker in biological sample. Ultrason. Sonochemistry 2019, 57, 233-241. [CrossRef] [PubMed]

23. Roy, N.; Yasmin, S.; Jeon, S. Effective electrochemical detection of dopamine with highly active molybdenum oxide nanoparticles decorated on 2, 6 diaminopyridine/reduced graphene oxide. Microchem. J. 2020, 153, 104501. [CrossRef]

24. Li, Y.; Han, X.; Yi, T.-F.; He, Y.-B.; Li, X. Review and prospect of NiCo2O4-based composite materials for supercapacitor electrodes. J. Energy Chem. 2019, 31, 54-78. [CrossRef]

25. Sui, Y.W.; Zhang, Y.M.; Hou, P.H.; Qi, J.Q.; Wei, F.X.; He, Y.Z.; Meng, Q.K.; Sun, Z. Three-dimensional $\mathrm{NiCo} 2 \mathrm{~S} 4$ nanosheets as high-performance electrodes materials for supercapacitors. J. Mater. Sci. 2017, 52, 7100-7109. [CrossRef]

26. Khalid, S.; Caoa, C.; Wang, L.; Zhu, Y. Microwave Assisted Synthesis of Porous NiCo2O4 Microspheres: Application as High Performance Asymmetric and Symmetric Supercapacitors with Large Areal Capacitance. Sci. Rep. 2016, 6, 22699. [CrossRef] [PubMed]

27. Chen, Z.; Zhao, H.; Zhang, J.; Xu, J. IrNi nanoparticle-decorated flower-shaped NiCo2O4 nanostructures: Controllable synthesis and enhanced electrochemical activity for oxygen evolution reaction. Sci. China Mater. 2016, 60, 119-130. [CrossRef]

28. Wen, Y.; Peng, S.; Wang, Z.; Hao, J.; Qin, T.; Lu, S.; Zhang, J.; He, D.; Fan, X.; Cao, G. Facile synthesis of ultrathin NiCo $2 \mathrm{~S} 4$ nano-petals inspired by blooming buds for high-performance supercapacitors. J. Mater. Chem. A 2017, 5, 7144-7152. [CrossRef]

29. Abdelkader, A.; Osman, A.I.; Halawy, S.A.; Mohamed, M.A. Preparation and characterization of mesoporous $\gamma$-Al2O3 recovered from aluminum cans waste and its use in the dehydration of methanol to dimethyl ether. J. Mater. Cycles Waste Manag. 2018, 20, 1428-1436. [CrossRef]

30. Muthumariappan, A.; Sakthivel, K.; Chen, S.-M.; Chen, T.-W.; Elgorban, A.M.; Elshikh, M.S.; Marraiki, N. Evaluating an effective electrocatalyst for the rapid determination of triptan drug (Maxalt ${ }^{\mathrm{TM}}$ ) from (mono and binary) transition metal (Co, Mn, CoMn, MnCo) oxides via electrochemical approaches. New J. Chem. 2020, 44, 605-613. [CrossRef]

(C) 2020 by the authors. Licensee MDPI, Basel, Switzerland. This article is an open access article distributed under the terms and conditions of the Creative Commons Attribution (CC BY) license (http://creativecommons.org/licenses/by/4.0/). 